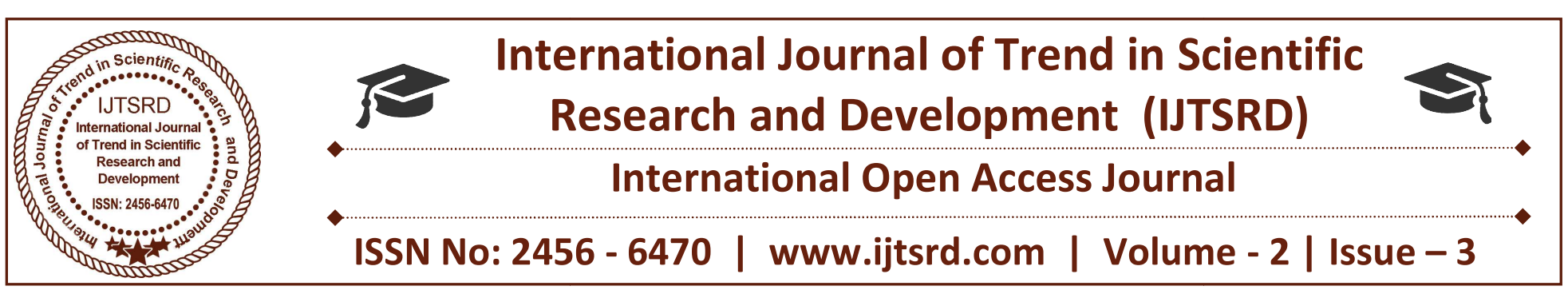

\title{
Employee Overseer Attendance Management and Business Analysis System
}

\author{
Silvia Sailekar, Mamta Panda, Chetan Rajput, Prof. Sonali Patil, Bhavin Chauhan \\ Computer Science Department, SRTCT's Faculty of Engineering \\ Pune, Maharashtra, India
}

\section{ABSTRACT}

An organized and systematic attendance of employees is the preferred requirement in industries currently. Employee attendance management of company plays an important position in the work of management of employees in company, this can help to urge employee to work sincerely on time, improve efficiency and improves the entire system. Based on attendance we can analyze business also. Android is easily adaptive in smart phones. The Attendance Management System and Business Analysis is a mobile computing software application. In this paper an android application is implemented for employee attendance based business analysis which focusses on an activity or function, which is based on management information system of the enterprise and business analysis is done based on it. It is an Employee Overseer Attendance Management and Business Analysis System(EOAMBAS) which is used in the computerization of attendance report. An EOAMBAS can handle roles such as Administration, Manager, and Field officers of the enterprise. This application is easy to use and economical in terms of time and cost. Business Intelligence is obtained by performing data analytics with the data obtained in database. The implemented android application is easily configurable as well as economical in time and capital. Additionally, it is easily adaptive on any android device and provides attendance marking and analysis based on it. Implemented system is extremely beneficial for the enterprise as it monitors the attendance as well as the turnover of enterprise dynamically at required intervals of time. Real time analysis is maintained in database.
Keywords: Attendance Analysis, Business Intelligence, EOAMBAS - Enterprise Overseer Attendance Management Business Analysis System, Graphical analysis

\section{INTRODUCTION}

In current period there is need of proper management of attendance and business analysis based on it also. Now a days, it is highly possible to adapt mobile computing in various applications. The portability, open source nature of smart phones and android development platform has made the development of application software for various environments as handy. Smartphone applications are resulted in paper less work, easy to use and time saving in nature.

Company face various problems when there is the employees are regardless of the attendance and due to which efficient capital benefits are also not gained. The attendance of the employees directly affect the capital. To overcome these issues an Enterprise Overseer Analysis System (EOAMBAS) is implemented which is an android application system which helps the enterprise to manage its employee attendance and the everyday turnover. Basically it is based on concepts of ERMS (Enterprise Resources Management System) which is used for business management as it manages more than one resource such as employees, clients, administrator and field officers. It is a unified system for management of products, bills, workforce, stocks, inventories and the business can predict the risks and challenges using ERMS modules [2]. EOAMBAS which is an android application is just a system which will manage the employees well so that the company works smoothly. It helps the business persons to take proper decisions 
regarding the business employee attendance and the financial issues of the company. It includes various modules like attendance, business analysis, management module and the complaint/remark module to help take proper decisions for betterment of the company. Developers now make more effort to integrate mobile devices with this system. This application is adaptable adapt to any processor easily, so the enterprise need to only use the existing devices for implementing this system. As it will use mobile devices it is easily portable and can be accessed easily on the mobile devices by any of the user.

This application helps to maintain the record of employees and manage the daily analysis. $E O A M B A S$ an application helps the users with following management point and it includes three user modules also as given below:

1) It helps the supervisors i.e. the field officers to mark attendance count of the employees which is directly stored in database so that later on the administrator retrieve it.

2) This application views daily attendance of the employees and also analysis based on it.

3) Overall business turnover till date is provided.

4) The turnover and analysis obtained through attendance is displayed through graph.

5) Graphs of analysis will be created for attendance and the turnover obtained.

6) As it is related to digitization process paper work is reduced and records as well as the business data is stored digitally.

7) Greater precision with charts that tracks down loss of business and helps to recover the losses immediately.

8) Providence of overview of daily management that how the business is working.

9) It helps the enterprise to keep accurate and proper records and enables the company to improve employee behaviour.

10) It also includes complaint and remark module regarding employees to the field officers and management.

11) The mechanism of application makes the work of employee attendance and business analysis easy and manageable
The application contains user modules as follows:

1) Administrator module: It manages the overall application and have access to all basic modules and the database. It creates the account and can modify the data related to certain modules. It has an authorised access to attendance and analysis of all field officers. It has access to compliant and remark module also.

2) Field Officer module: It has access to attendance module and has a overview to analysis and manages the compliant module.

3) Management module: It a read only user. Business analysis and attendance management is viewed to the management but it cannot modify.

The above three modules user modules include there basic module in the application.

Following are the basic modules are:

1) Attendance module: It helps the field officers to mark the count of the employees present every day. It also shows analysis of the attendance to tally the benefits and improvement.

2) Business Analysis module: It provides the information of everyday turnover of the company. It helps the management for proper decision making. It also manages the financial benefits of enterprise

3)Complaint/Remark module: Various complaints related to employees is entered in this module which will directly help the management to take consummate decisions. Remarks by client is given in this module.

Thus the EOAMBAS system an android application is extremely useful by enterprise to make proper decisions and manage the employees well.

\section{Literature Survey}

Now a days, it is highly possible to adapt mobile computing in various applications. Smartphone applications are resulted in paper less work, easy to use and time saving in nature[1].Traditional attendance marking system gained time and cost and increased paper work too. To overcome this problems digitization of attendance brought in market.An enterprise resource management model 
for business intelligence, data mining and predictive analytics shows implementation of purposed ERMS model which have modules designed for Employees, Attendance, Accounting, feedbacks and users. In this ERMS framework data is handled by designing an automated data handling algorithm. To build in the feature of time-in and time-out a calendar API has been consumed for attendance marking of employees within the enterprise. In existence An Android based Employee Tracking System is implemented which can use different modules, and main two apps are employee app and server app. Employee time tracking phone uses data which will be stored in centralized server. Mobile device which is on the Head of Department's table should be an Android device and the administrative manager can get the alert through messages only. This system only does employee tracking and does not access its analysis which necessary for the organization. The Analysis of Data Collected by Time and Attendance Systems is mandatory. The implemented system is an overcome to the existing system as it gives exact data and analysis and give the accurate count.

Client management system helps to manage the clients and their preferences[3]. Feedback system collects the feedback of clients[3]. Clients are essential for success of business. These modules were not present in the existing system so to overcome it we have implemented modules which give accurate attendance count. The attendance module manages the assets and liabilities of the business. Lack of complaints and remark system cause inconsistency in the working of enterprise.

Moreover, the topmost executives of the company would not able to know the current state of the company, to know the current state he has to ask the employees to prepare reports[3].The implementation is an advantage for the existing system.

\section{Implementation System :}

The EOAS an android application consists of user modules and its sub-modules. The users modules are Administrator module, FO module and Management module. The Admin has control over the entire application. The FO is responsible for marking the attendance of employees which is analysed for business and it also takes complaints and remarks from client to improve the quality of service of the enterprise. The data is stored on firebase a cloud platform. The functions performed by admin is updated firebase and the data is given to server database for backup purpose. The modules are integrated together so there will be ease in flow between modules. The application gives better performance due to consummate data flow. The application is developed on agile process which is standard model for development of software or application in usage in corporate world. Centralized storage system called as firebase is used for storing data. The data gained by mining is used for analysing business benefits. This helps the company for increasing its profits and drag down the flaws. Analysis of business helps identifying opportunities for innovation. Business intelligence gives optimal usage of resources and succeed in competition. Enterprises opportunities and risks can be evaluated [2]. The FO marks the attendance and based on it analysis is done. The data is stored in firebase and is analysed and the benefits are shown in graphical form.

As mentioned above the system contains user modules let us discuss it in detail. One of its user module is Administrator module.

1) Admin module: This module controls the entire application. Creation of accounts of FOs(Field Officers) and management is done by this module. The user can login by using its email id which is registered as administrator. The admin has access to the most of the modules. The admin has navigation activity which contains fragments like remove client and add client. It has authority to add client for a particular FO. It can also delete a client of the respective FO. The transactions done by admin is stored in centralized database called as firebase. Admin has authentication to view it. Analysis is done based on the data stored in firebase. The following fig.1(a) shows the navigation activity of admin. 


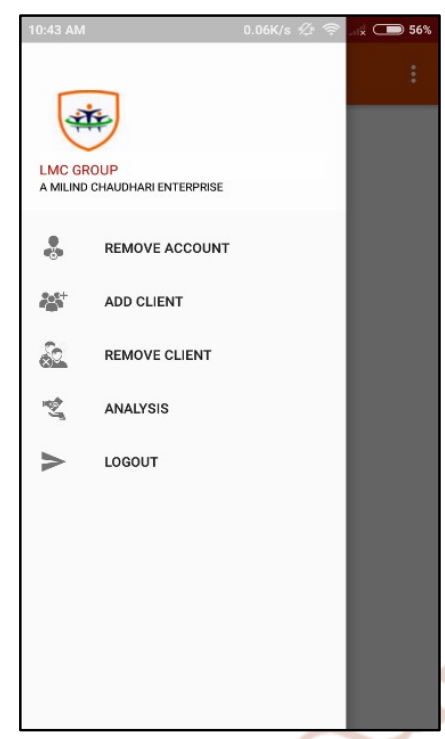

Fig No. 1(a)

on it analysis is done. In analysis module graphical representation of business benefits is shown. In Complaint and Remark module client can enter complaints and remarks regarding to the field officer on which actions can be taken later on it so that quality of service of the company is improved. Fig No. 2(a) gives the navigation activity of FO module.

The admin adds a client by selecting add client fragment and various fields get displayed that is mandatory to fill. The following fig no.1(b) shows the various fields that is to be entered or filled.

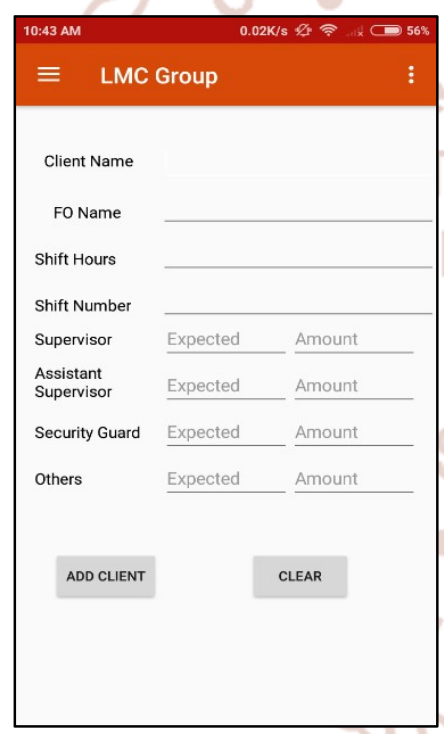

Fig No. 1(b)
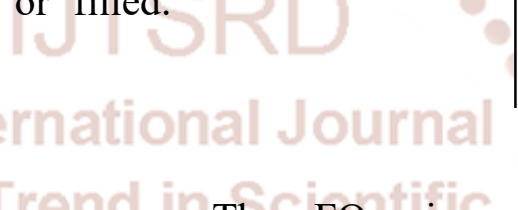

The FO gives attendance count of particular employees under him. The attendance module tab gives various fields which are mandatory to record the attendance. Fig No. 2(b) shows the attendance tab activity which contains the estimated count of employees and the present count of employees. According to that count the business analysis is done. The enterprise gets the data through which it comes to know whether the enterprise is gaining improvement or decrement in business.

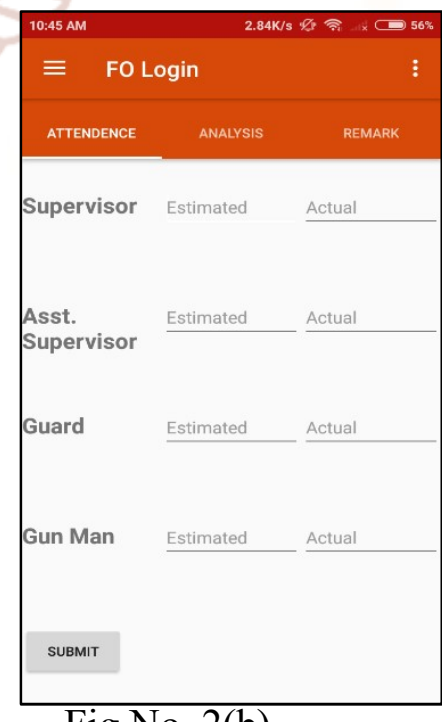

Fig No. 2(b)

Fig No.2(a)

No.2(a)

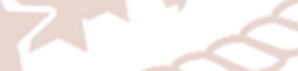

2) FO (Field Officer) module: This module is used by field officers related to different fields. The user registered as Field Officer can login in this module. The Field officer visit the sites allotted to them and mark the attendance count of the employees present on that particular site. It contains navigation activity which include client names under that particular Field officer. It has sub modules as Attendance, Analysis and Remark/Complaints. In attendance module it marks the attendance of employees and enters the data related in the particular field. Its provides attendance count of employees and based

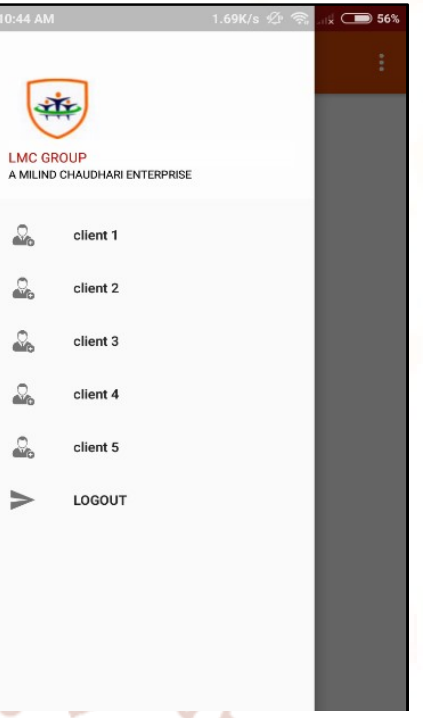


In Remark/Complaints module the clients can enters the remark regarding a respective $\mathrm{FO}$ (Field Officer) so that the enterprise will take effective measures regarding it. Fig No. 2(c) displays the remark tab activity of FO module.

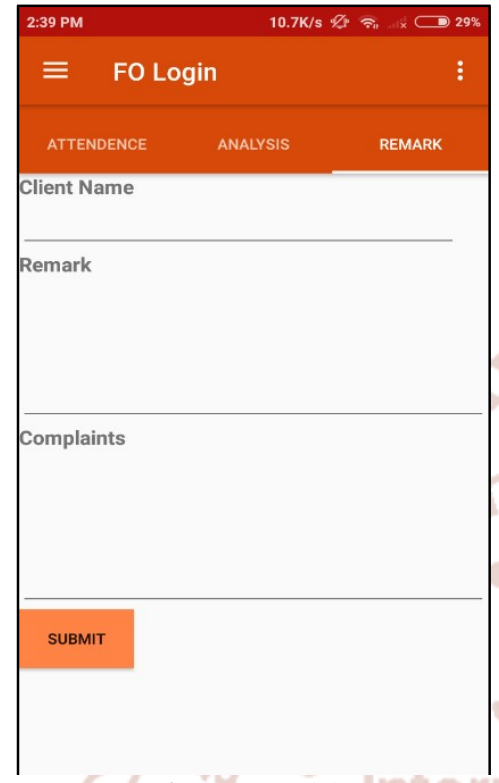

Fig No. 2(c)

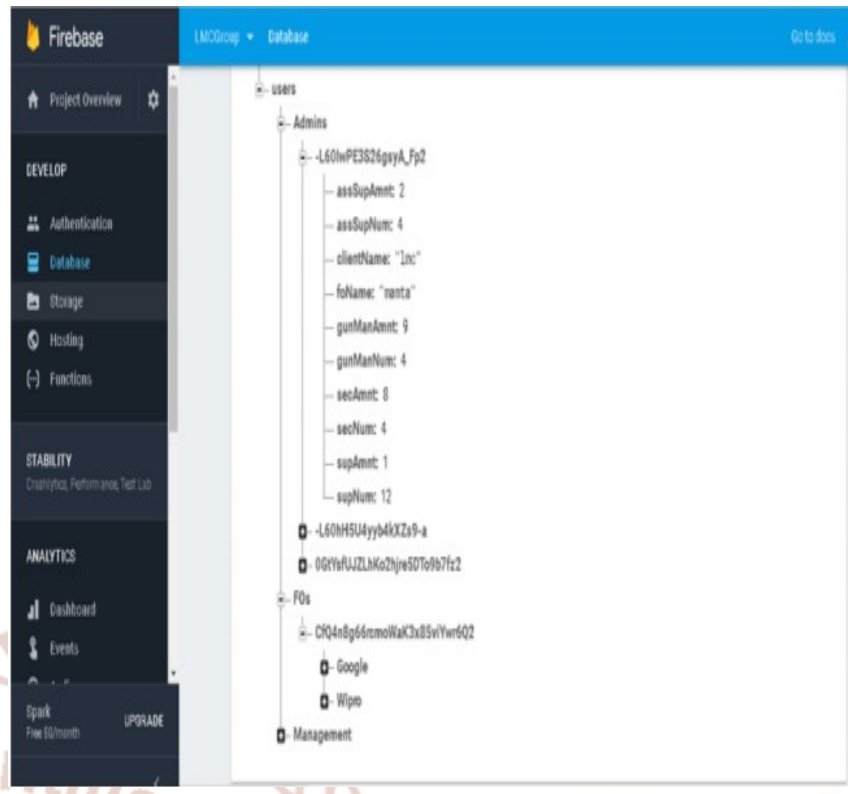

Fig No. 3(a)

\section{Implementation}

The development of Enterprise Overseer Attendance Management Business

Analysis System(EOAMBAS) in done in Android Studio. For implementation of android application the programming languages used are Core and Advanced

3) Management module: This module is for management staff. They are passives users as in read only users which cannot modify data. The data mined from firebase is analysed and represented graphically in analysis module and this is viewed to management module to take cost effective decisions based on the analysed data through business benefits.

The data which is processed on application is stored at local database firebase later on it is backed up on main server. The clients which are added are displayed on firebase. The attendance count is recorded on the database through analysis is done and is displayed using graphical representation. Firebase is used as local server. The data which is updated is shown on firebase fig no. 3(a) shows the local server and updated data.
Java and framework is Android Studio AP. The layout is processed by using XML which is the Graphical User Interface(GUI).

The data which in entered in application is stored in database. Firebase which is a real time database is used as a local server for database. The data is stored in firebase then backed up on the main server of the enterprise after a period. The attendance count entered in application is stored in database, using that information an analysis graph is created which displays the analysis of expenditure in graphical format. To represent analysis through graphs Graph view has been used.

\section{Future Scope:}

To handle the data the enterprise had to use third party communication via social networking. Whereas, now the EOAS provides direct access for data manipulation making the system easy to use and reliable. Later on to upgrade the application, tracking attendance system can be used which will track the location and enhance the data consistency. Further to improve communication within the enterprise a conversation module can be added which will also 
look after proper synchronization of the enterprise. To improve the security, biometrics can be used for accessing the system and even as an authentication. These improvement will increase the quality of service as well as business intelligence and better management of employees.

\section{Acknowledgement:}

It gives us great pleasure in presenting the preliminary research on

Employee Overseer Attendance Management and Business Analysis System.We would like to take this opportunity to thank our Guide Prof.Sonali Patil and External Guide Mr.Sherkhan Pathan for giving us all the help and guidance we needed. We are really grateful to them for their kind support. Their valuable suggestions were very helpful.

\section{Result}

An Employee overseer attendance management and business analysis is implemented which provides accurate and proper and consummate management of attendance of employees and provide business analysis also. It includes Admin, $F O$ and Management module which function in this application. It is efficient and configurable on any android device. This application has reduced paper work of the enterprise. It has produce an ease for business intelligence.

\section{Reference}

1) Sivaram Ponnusamy "Design and Development of Android based Attendance Management System" researchgate :September 2014, available https://www.researchgate.net/publication/315696 934_Design_and_Development_of_Android_bas ed_Attendance_Management_System?enrichId $=r$ greq529d3aaee57277ff1f85f32c59fb732XXX\&e nrichSource $=$ Y292ZXJQYWdlOzMxNTY5Njkz NDtBUzo0Nzc0OTc1NzkwNTMwNTdAMTQ5 MDg1NTcwMjQ5Mg\%3D\%3D\&el=1_x_2\&_es $\mathrm{c}=$ publicationCoverPdf.

2) "An Enterprise Resource Management Model for Business Intelligence, Data Mining and Predictive Analytics"Athul Jayaram, Swati Singal Amity University, Uttar Pradesh

3) “An Enterprise Resource Management Model for Smart Business Analysis Based on Employee Monitoring System" Prof. Hariprasad Mal1 Mamta Panda2 Bhavin Chauhan3 Chetan Rajput4 Silvia Sailekar5 1,2,3,4,5SRTCT's Faculty of Engineering. 